\title{
Article \\ Comparative Chemical Profiles and Phytotoxic Activity of Essential Oils of Two Ecospecies of Pulicaria undulata (L.) C.A.Mey
}

\author{
Ahmed M. Abd-ELGawad 1,2,*, Saud L. Al-Rowaily ${ }^{1}$, Abdulaziz M. Assaeed ${ }^{1} \mathbb{D}$, Yasser A. EI-Amier $^{2} \mathbb{D}$, \\ Abd El-Nasser G. El Gendy ${ }^{3}{ }^{(D}$, Elsayed Omer ${ }^{3}$, Dakhil H. Al-Dosari ${ }^{1}$, Giuliano Bonanomi ${ }^{4}$, Hazem S. Kassem ${ }^{5}$ (D) \\ and Abdelsamed I. Elshamy ${ }^{6}$ iD
}

Citation: Abd-ELGawad, A.M.; Al-Rowaily, S.L.; Assaeed, A.M.; EI-Amier, Y.A.; El Gendy, A.E.-N.G.; Omer, E.; Al-Dosari, D.H.; Bonanomi, G.; Kassem, H.S.; Elshamy, A.I. Comparative Chemical Profiles and Phytotoxic Activity of Essential Oils of Two Ecospecies of Pulicaria undulata (L.) C.A.Mey. Plants 2021, 10, 2366. https://doi.org/ 10.3390/plants10112366

Academic Editors: Hazem Salaheldin Elshafie, Laura De Martino and Adriano Sofo

Received: 11 October 2021

Accepted: 28 October 2021

Published: 3 November 2021

Publisher's Note: MDPI stays neutral with regard to jurisdictional claims in published maps and institutional affiliations.

Copyright: (c) 2021 by the authors. Licensee MDPI, Basel, Switzerland. This article is an open access article distributed under the terms and conditions of the Creative Commons Attribution (CC BY) license (https:/ / creativecommons.org/licenses/by/ $4.0 /)$.
1 Plant Production Department, College of Food and Agriculture Sciences, King Saud University, P.O. Box 2460, Riyadh 11451, Saudi Arabia; srowaily@ksu.edu.sa (S.L.A.-R.); assaeed@ksu.edu.sa (A.M.A.); dadosari@gmail.com (D.H.A.-D.)

2 Department of Botany, Faculty of Science, Mansoura University, Mansoura 35516, Egypt; yasran@mans.edu.eg

3 Medicinal and Aromatic Plants Research Department, National Research Centre, 33 El Bohouth St., Dokki, Giza 12622, Egypt; aggundy_5@yahoo.com (A.E.-N.G.E.G.); sayedomer2001@yahoo.com (E.O.)

4 Department of Agriculture, University of Naples Federico II, Portici, 80055 Naples, Italy; giuliano.bonanomi@unina.it

5 Department of Agricultural Extension and Rural Society, College of Food and Agriculture Sciences, King Saud University, Riyadh 11451, Saudi Arabia; hskassem@ksu.edu.sa

6 Department of Natural Compounds Chemistry, National Research Centre, 33 El Bohouth St., Dokki, Giza 12622, Egypt; elshamynrc@yahoo.com

* Correspondence: aibrahim2@ksu.edu.sa; Tel.: +966-562-680-864

Abstract: The Asteraceae (Compositae) family is one of the largest angiosperm families that has a large number of aromatic species. Pulicaria undulata is a well-known medicinal plant that is used in the treatment of various diseases due to its essential oil (EO). The EO of both Saudi and Egyptian ecospecies were extracted via hydrodistillation, and the chemical compounds were identified by GCMS analysis. The composition of the EOs of Saudi and Egyptian ecospecies, as well as other reported ecospecies, were chemometrically analyzed. Additionally, the phytotoxic activity of the extracted EOs was tested against the weeds Dactyloctenium aegyptium and Bidens pilosa. In total, 80 compounds were identified from both ecospecies, of which 61 were Saudi ecospecies, with a preponderance of $\beta$-pinene, isoshyobunone, 6-epi-shyobunol, $\alpha$-pinene, and $\alpha$-terpinolene. However, the Egyptian ecospecies attained a lower number (34 compounds), with spathulenol, hexahydrofarnesyl acetone, $\alpha$-bisabolol, and $\tau$-cadinol as the main compounds. The chemometric analysis revealed that the studied ecospecies and other reported species were different in their composition. This variation could be attributed to the difference in the environmental and climatic conditions. The EO of the Egyptian ecospecies showed more phytotoxic activity against D. aegyptium and B. pilosa than the Saudi ecospecies. This variation might be ascribed to the difference in their major constituents. Therefore, further study is recommended for the characterization of authentic materials of these compounds as allelochemicals against various weeds, either singular or in combination.

Keywords: allelopathy; Pulicaria crispa; chemometric analysis; chemotype; Asteraceae

\section{Introduction}

Taxa belonging to Pulicaria (Asteraceae Family) are widely distributed in Asia, Africa, and Europe. These plants are considered very important medicinal plants due to their traditional applications around the world, in addition to the presence of interesting metabolites comprising mono-, sesqui-, and diterpenoids, as well as phenolic and flavonoids [1-4].

The Egyptian widespread desert plant, Pulicaria undulata (L.) (syn. Pulicaria crispa (Forssk.) Benth et Hook), was documented as a very important traditional plant for the 
treatment of diabetes, abscesses, cardiac and skin diseases, and chills [5]. In Egypt, this plant was used as a herbal tea for inflammation treatment, in addition to insect repellent [4].

Numerous pharmaceutical activities were described for different extracts and ingredients of this plant such as antioxidant [6-8], neuroprotective [9], antiulcer [10], antiacetylcholinesterase [8], anticancer [11], and $\alpha$-glucosidase inhibitory activity [12]. These biological activities of $P$. undulata were ascribed to different classes of identified chemical compounds such as terpenes [4,12-15], flavonoids [7,16], and sterols [11]. The essential oil (EO) of P. undulata exhibited various potent biological activities such as antiproliferative, antioxidant [6,15], anticancer [8], antibacterial [13], and cytotoxic [12].

Many documents have been published concerning the chemical characterization EOs of different ecospecies of P. undulata from different countries such as Sudan [6,17], Iran [15,18,19], Algeria [14], Yemen [13], and Egypt [8,16,20]. However, by comparing all these ecospecies, there was evidence that their EOs were different either in quality or quantity. This deduced that the biosynthesis of the natural metabolites including EOs in the plant kingdom is correlated with environmental and climatic conditions, in addition to genetic variability [21-23]. The present study aimed to analyze and compare the EO profiles of two ecospecies of P. undulata growing in Saudi Arabia and Egypt, assess phytotoxicity against the noxious weeds Dactyloctenium aegyptium and Bidens pilosa, as well as holistically categorize their EOs with other reported ecospecies using chemometric tools.

\section{Results and Discussion}

\subsection{Yields and Chemical Constituents of P. undulata EOs}

The aerial parts of Saudi and Egyptian P. undulata (150 g each) were subjected separately to the hydrodistillation for $3 \mathrm{~h}$ in Clevenger-type apparatus, provided pale yellow oil with an average yield of $0.43 \%$ and $0.36 \%(v / w)$, respectively. The yields of EOs in our study were comparable to those reported from other Egyptian ecospecies $(0.23-0.60 \%)[9,16,20]$. However, the yield of the present $P$. undulata ecospecies was lower than that reported in previous studies for other ecospecies such as Yemeni $(2.10 \%)$ [13], Iranian $(0.50-1.34 \%)[15,19,24]$, Sudanian $(1.40-2.50 \%)$ [6,17], and Algerian ecospecies $(1.20 \%)$ [14]. These variations in the yield of the EOs might be attributed to the difference in the geographical region, in addition to the environmental conditions such as soil, climate, as well as genetic pool [22,25-27].

In total, 80 compounds were characterized depending upon GC-MS analysis of the two EOs of P. undulata including 61 and 34 compounds from Saudi and Egyptian ecospecies, respectively. The identified constituents were classified into eight classesnamely, (i) monoterpene hydrocarbons, (ii) oxygenated monoterpenes, (iii) sesquiterpene hydrocarbons, (iv) oxygenated sesquiterpenes, (v) carotenoid-derived compounds, (vi) apocarotenoid-derived compounds, (vii) nonoxygenated hydrocarbons, and (viii) oxygenated hydrocarbons, (Figure 1a). Oxygenated sesquiterpenes were the most represented class-they represented $55.03 \%$ and $40.34 \%$ of the total oil of the Egyptian and Saudi ecospecies, respectively. Monoterpenes were determined with a high content $(39.46 \%)$ of the EO of Saudi ecospecies, while it represented a minor class in Egyptian ecospecies $(6.70 \%)$. Additionally, hydrocarbons represented $13.32 \%$ of the total EO content of the Egyptian eco-sample, while completely absent in the Saudi plant sample. Overall, the Egyptian ecospecies had oxygenated compounds as the main elements, while non-oxygenated compounds were represented as the main constituents of Saudi ecospecies (Figure 1b). The identified compounds, accounting for $97.22 \%$ and $97.61 \%$, respectively, of overall $\mathrm{EO}$ mass, in addition to their retention times, and literature and experimental Kovats indices are presented in Table 1. 


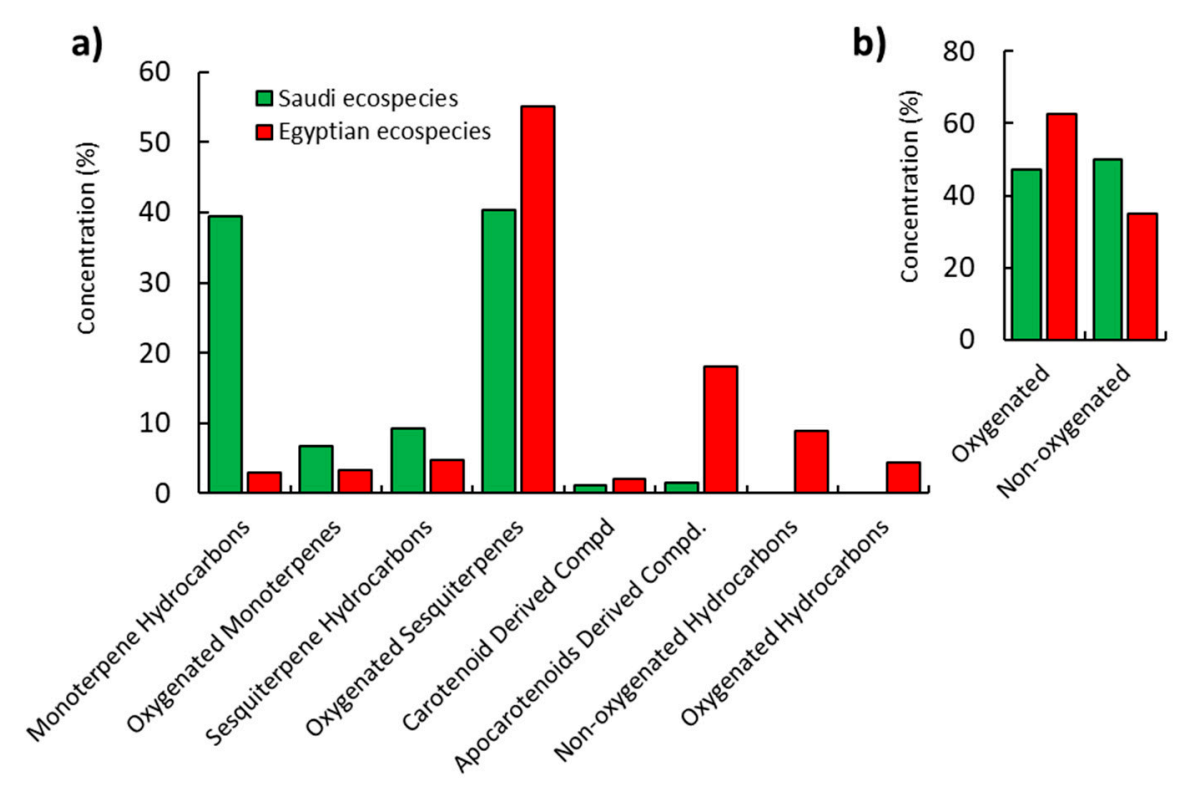

Figure 1. Classification of the chemical compounds of Pulicaria undulata EOs of Saudi and Egyptian ecospecies. (a) various classes and (b) oxygenated and non-oxygenated compounds.

Table 1. Chemical constituents of the EOs of the aerial parts of Saudi and Egyptian ecospecies of Pulicaria undulata.

\begin{tabular}{|c|c|c|c|c|c|c|c|}
\hline \multirow{2}{*}{ No. } & \multirow{2}{*}{$\mathbf{R t}^{\mathbf{a}}$} & \multicolumn{2}{|c|}{ Relative Conc. (\%) } & \multicolumn{2}{|c|}{ KI } & \multirow{2}{*}{ Compound Name } & \multirow{2}{*}{ Identification } \\
\hline & & $\mathbf{S A}^{\mathbf{b}}$ & $\mathrm{EG}^{\mathrm{c}}$ & Lit. $^{d}$ & Exp. $^{\mathrm{e}}$ & & \\
\hline \multicolumn{8}{|c|}{ Monoterpene Hydrocarbons } \\
\hline 1 & 4.05 & $0.14 \pm 0.01$ & - & 931 & 931 & $\alpha$-Thujene & $\mathrm{KI}$ and MS \\
\hline 2 & 4.20 & $5.08 \pm 0.06$ & $0.91 \pm 0.01$ & 939 & 940 & $\alpha$-Pinene & $\mathrm{KI}$ and MS \\
\hline 3 & 4.58 & $0.15 \pm 0.02$ & - & 953 & 951 & Camphene & KI and MS \\
\hline 4 & 5.07 & $0.76 \pm 0.04$ & - & 976 & 975 & Sabinene & $\mathrm{KI}$ and MS \\
\hline 5 & 5.21 & $21.14 \pm 0.12$ & $1.32 \pm 0.05$ & 980 & 980 & $\beta$-Pinene & $\mathrm{KI}$ and MS \\
\hline 6 & 6.19 & $0.65 \pm 0.01$ & - & 1031 & 1030 & Limonene & $\mathrm{KI}$ and MS \\
\hline 7 & 6.50 & $7.70 \pm 0.08$ & - & 1064 & 1063 & $\gamma$-Terpinene & KI and MS \\
\hline 8 & 8.09 & $3.84 \pm 0.05$ & $0.81 \pm 0.03$ & 1088 & 1086 & $\alpha$-Terpinolene & $\mathrm{KI}$ and MS \\
\hline \multicolumn{8}{|c|}{ Oxygenated Monoterpenes } \\
\hline 9 & 5.50 & $0.46 \pm 0.03$ & - & 991 & 990 & Dehydro-1,8-cineole & KI and MS \\
\hline 10 & 5.92 & $0.22 \pm 0.01$ & - & 1005 & 1005 & $\alpha$-Phellandrene & $\mathrm{KI}$ and MS \\
\hline 11 & 6.01 & $0.13 \pm 0.01$ & - & 1129 & 1129 & $p$-2-Menthen-1-ol & $\mathrm{KI}$ and MS \\
\hline 12 & 9.45 & $0.27 \pm 0.02$ & - & 1131 & 1132 & trans- $p$-Mentha-2,8-dienol & $\mathrm{KI}$ and MS \\
\hline 13 & 9.96 & $0.15 \pm 0.01$ & - & 1137 & 1138 & $\beta$-Nopinone & KI and MS \\
\hline 14 & 10.05 & $0.27 \pm 0.02$ & - & 1139 & 1139 & Pinocarveol & KI and MS \\
\hline 15 & 10.23 & $0.21 \pm 0.01$ & - & 1140 & 1140 & cis-Verbenol & $\mathrm{KI}$ and MS \\
\hline 16 & 10.72 & $0.27 \pm 0.03$ & - & 1143 & 1145 & Camphor & $\mathrm{KI}$ and MS \\
\hline 17 & 10.99 & $0.28 \pm 0.02$ & - & 1162 & 1161 & Pinocarvone & $\mathrm{KI}$ and MS \\
\hline 18 & 11.28 & $0.28 \pm 0.01$ & - & 1165 & 1167 & endo-Borneol & $\mathrm{KI}$ and MS \\
\hline 19 & 11.82 & $1.20 \pm 0.04$ & - & 1177 & 1179 & Terpinen-4-ol & $\mathrm{KI}$ and MS \\
\hline 20 & 13.04 & $0.20 \pm 0.02$ & - & 1194 & 1193 & Myrtenal & $\mathrm{KI}$ and MS \\
\hline 21 & 13.51 & $0.11 \pm 0.01$ & - & 1228 & 1229 & $\alpha$-Citronellol & $\mathrm{KI}$ and MS \\
\hline 22 & 16.79 & $0.14 \pm 0.01$ & - & 1321 & 1319 & Isopulegol acetate & KI and MS \\
\hline 23 & 17.33 & $0.48 \pm 0.01$ & - & 1354 & 1356 & Citronellyl acetate & $\mathrm{KI}$ and MS \\
\hline 24 & 17.84 & $0.26 \pm 0.01$ & $3.36 \pm 0.07$ & 1258 & 1259 & Carvotanacetone & $\mathrm{KI}$ and MS \\
\hline 25 & 20.21 & $2.50 \pm 0.05$ & - & 1326 & 1326 & Myrtenyl acetate & $\mathrm{KI}$ and MS \\
\hline
\end{tabular}


Table 1. Cont.

\begin{tabular}{|c|c|c|c|c|c|c|c|}
\hline \multirow{2}{*}{ No. } & \multirow{2}{*}{$\mathbf{R t}^{\mathbf{a}}$} & \multicolumn{2}{|c|}{ Relative Conc. (\%) } & \multicolumn{2}{|c|}{ KI } & \multirow{2}{*}{ Compound Name } & \multirow{2}{*}{ Identification } \\
\hline & & $\mathrm{SA}^{\mathrm{b}}$ & $\mathrm{EG}^{\mathrm{c}}$ & Lit. ${ }^{d}$ & Exp. ${ }^{e}$ & & \\
\hline \multicolumn{8}{|c|}{ Sesquiterpene Hydrocarbons } \\
\hline 26 & 16.34 & $0.58 \pm 0.01$ & - & 1377 & 1375 & Berkheyaradulen & $\mathrm{KI}$ and MS \\
\hline 27 & 17.48 & $3.63 \pm 0.04$ & $1.17 \pm 0.06$ & 1409 & 1410 & $\alpha$-Gurjunene & $\mathrm{KI}$ and $\mathrm{MS}$ \\
\hline 28 & 17.70 & $0.62 \pm 0.03$ & - & 1418 & 1418 & trans-Caryophyllene & KI and MS \\
\hline 29 & 18.47 & $0.78 \pm 0.02$ & - & 1439 & 1437 & $\alpha$-Guaiene & KI and MS \\
\hline 30 & 18.69 & $0.88 \pm 0.04$ & $0.81 \pm 0.01$ & 1455 & 1456 & $\alpha$-Humulene & KI and MS \\
\hline 31 & 19.63 & $0.13 \pm 0.01$ & $2.76 \pm 0.05$ & 1473 & 1472 & $\gamma$-Gurjunene & KI and MS \\
\hline 32 & 19.85 & $0.18 \pm 0.01$ & - & 1480 & 1480 & Germacrene-D & KI and MS \\
\hline 33 & 20.77 & $0.37 \pm 0.01$ & - & 1483 & 1484 & $\alpha$-Curcumene & $\mathrm{KI}$ and MS \\
\hline 34 & 21.21 & $0.51 \pm 0.01$ & - & 1499 & 1500 & $\alpha$-Muurolene & KI and MS \\
\hline 35 & 21.78 & $1.49 \pm 0.05$ & - & 1524 & 1525 & $\delta$-Cadinene & KI and MS \\
\hline \multicolumn{8}{|c|}{ Oxygenated Sesquiterpenes } \\
\hline 36 & 20.95 & $1.54 \pm 0.03$ & - & 1515 & 1514 & Shyobunone & $\mathrm{KI}$ and MS \\
\hline 37 & 21.67 & $6.51 \pm 0.07$ & $2.31 \pm 0.02$ & 1517 & 1517 & 6-epi-Shyobunol & $\mathrm{KI}$ and MS \\
\hline 38 & 22.37 & $0.12 \pm 0.01$ & - & 1518 & 1518 & 6-epi-Shyobunone & KI and MS \\
\hline 39 & 23.19 & $0.41 \pm 0.01$ & - & 1563 & 1562 & Citronellyl iso-valerate & KI and MS \\
\hline 40 & 23.47 & $3.33 \pm 0.08$ & $0.87 \pm 0.01$ & 1564 & 1564 & trans-Nerolidol & KI and MS \\
\hline 41 & 23.66 & $7.67 \pm 0.05$ & $1.63 \pm 0.04$ & 1571 & 1572 & Isoshyobunone & $\mathrm{KI}$ and MS \\
\hline 42 & 23.78 & $3.43 \pm 0.04$ & $30.86 \pm 0.12$ & 1575 & 1575 & Spathulenol & KI and MS \\
\hline 43 & 24.13 & $0.17 \pm 0.01$ & - & 1581 & 1582 & Caryophyllene oxide & KI and MS \\
\hline 44 & 24.52 & $4.82 \pm 0.09$ & $0.95 \pm 0.03$ & 1584 & 1586 & 7-Hydroxyfarnesen & KI and MS \\
\hline 45 & 24.62 & $0.51 \pm 0.01$ & $1.25 \pm 0.02$ & 1595 & 1595 & Salvial-4(14)-en-1-one & KI and MS \\
\hline 46 & 24.78 & $0.84 \pm 0.02$ & - & 1596 & 1598 & Veridiflorol & $\mathrm{KI}$ and MS \\
\hline 47 & 24.85 & $2.41 \pm 0.05$ & - & 1608 & 1610 & Humuladienone & KI and MS \\
\hline 48 & 24.97 & $0.55 \pm 0.01$ & - & 1613 & 1613 & Longifolenaldehyde & KI and MS \\
\hline 49 & 25.12 & $0.16 \pm 0.01$ & - & 1625 & 1627 & Isospathulenol & KI and MS \\
\hline 50 & 25.29 & $0.88 \pm 0.04$ & - & 1621 & 1620 & Fonenol & $\mathrm{KI}$ and MS \\
\hline 51 & 25.43 & $0.74 \pm 0.03$ & - & 1641 & 1640 & Cubenol & KI and MS \\
\hline 52 & 25.58 & $0.76 \pm 0.02$ & $3.65 \pm 0.07$ & 1642 & 1642 & $\tau$-Cadinol & KI and MS \\
\hline 53 & 25.65 & $0.38 \pm 0.02$ & - & 1643 & 1644 & $\tau$-Muurolol & KI and MS \\
\hline 54 & 25.98 & $1.39 \pm 0.06$ & - & 1649 & 1650 & $\beta$-Eudesmol & KI and MS \\
\hline 55 & 26.88 & $0.29 \pm 0.01$ & - & 1653 & 1654 & $\alpha$-Cadinol & KI and MS \\
\hline 56 & 27.04 & $1.74 \pm 0.08$ & - & 1668 & 1668 & Cedr-8-en-13-ol & $\mathrm{KI}$ and $\mathrm{MS}$ \\
\hline 57 & 27.5 & $0.40 \pm 0.02$ & - & 1671 & 1670 & Calarene epoxide & $\mathrm{KI}$ and MS \\
\hline 58 & 28.61 & $0.18 \pm 0.01$ & - & 1682 & 1680 & Ledene oxide-(I) & $\mathrm{KI}$ and MS \\
\hline 59 & 28.89 & $1.11 \pm 0.03$ & $6.34 \pm 0.05$ & 1683 & 1683 & $\alpha$-Bisabolol & $\mathrm{KI}$ and MS \\
\hline 60 & 30.66 & - & $1.53 \pm 0.03$ & 1690 & 1693 & $\begin{array}{c}\text { 6-Isopropenyl-4,8a- } \\
\text { dimethyl-1,2,3,5,6,7,8,8a- } \\
\text { octahydro-naphthalen-2-ol } \\
\text { 4,4-Dimethyl- }\end{array}$ & $\mathrm{KI}$ and MS \\
\hline 61 & 31.41 & - & $4.68 \pm 0.07$ & 2257 & 2259 & $\begin{array}{l}\text { tetracyclo[6.3.2.0(2,5).0(1,8)] } \\
\text { tridecan-9-ol }\end{array}$ & KI and MS \\
\hline 62 & 33.35 & - & $0.96 \pm 0.01$ & 2462 & 2463 & Isocalamendiol & $\mathrm{KI}$ and MS \\
\hline \multicolumn{8}{|c|}{ Carotenoid Derived Compounds } \\
\hline 63 & 16.10 & - & $0.97 \pm 0.04$ & 1279 & 1280 & Vitispirane & KI and MS \\
\hline 64 & 16.45 & - & $1.06 \pm 0.04$ & 1288 & 1287 & Dihydroedulan II & KI and MS \\
\hline 65 & 23.29 & $0.64 \pm 0.03$ & - & 1444 & 1445 & Citronellyl propionate & KI and MS \\
\hline \multicolumn{8}{|c|}{ Apocarotenoid Derived Compounds } \\
\hline 66 & 38.29 & 1.51 & $18.12 \pm 0.11$ & 1845 & 1845 & $\begin{array}{l}\text { Hexahydrofarnesyl } \\
\text { acetone }\end{array}$ & KI and MS \\
\hline
\end{tabular}


Table 1. Cont.

\begin{tabular}{|c|c|c|c|c|c|c|c|}
\hline \multirow{2}{*}{ No. } & \multirow{2}{*}{$\mathbf{R t}^{\mathbf{a}}$} & \multicolumn{2}{|c|}{ Relative Conc. (\%) } & \multicolumn{2}{|c|}{ KI } & \multirow{2}{*}{ Compound Name } & \multirow{2}{*}{ Identification } \\
\hline & & $\mathbf{S A}^{\mathbf{b}}$ & $E^{c}$ & Lit. $^{d}$ & Exp. $^{\mathrm{e}}$ & & \\
\hline \multicolumn{8}{|c|}{ Non-oxygenated Hydrocarbons } \\
\hline 67 & 32.32 & - & $1.08 \pm 0.06$ & 1533 & 1535 & $\begin{array}{l}\text { 2,6,10-Trimethyl- } \\
\text { tetradecane }\end{array}$ & $\mathrm{KI}$ and MS \\
\hline 68 & 33.97 & - & $0.97 \pm 0.01$ & 1885 & 1883 & $\begin{array}{l}2,6,10,15 \text {-Tetramethyl- } \\
\text { heptadecane }\end{array}$ & $\mathrm{KI}$ and MS \\
\hline 69 & 39.53 & - & $1.57 \pm 0.05$ & 1900 & 1900 & n-Nonadecane & KI and MS \\
\hline 70 & 44.39 & - & $0.66 \pm 0.04$ & 2200 & 2200 & n-Docosane & $\mathrm{KI}$ and MS \\
\hline 1 & 46.11 & - & $1.05 \pm 0.03$ & 2300 & 2300 & $n$-Tricosane & KI and MS \\
\hline 72 & 46.35 & - & $1.28 \pm 0.07$ & 2500 & 2500 & $n$-Pentacosane & $\mathrm{KI}$ and MS \\
\hline 73 & 52.20 & - & $1.49 \pm 0.05$ & 2900 & 2900 & n-Nonacosane & $\mathrm{KI}$ and MS \\
\hline 74 & 57.64 & - & $0.42 \pm 0.04$ & 3000 & 3000 & $n$-Triacontane & $\mathrm{KI}$ and MS \\
\hline 75 & 57.71 & - & $0.46 \pm 0.03$ & 3200 & 3200 & $n$-Dotriacontane & $\mathrm{KI}$ and MS \\
\hline \multicolumn{8}{|c|}{ Oxygenated Hydrocarbons } \\
\hline 76 & 37.85 & - & $3.73 \pm 0.07$ & 1942 & 1945 & cis-9-Hexadecenoic acid & $\mathrm{KI}$ and MS \\
\hline 77 & 47.39 & - & $0.29 \pm 0.01$ & 2135 & 2132 & 9,12-Octadecadienoic acid & KI and MS \\
\hline \multirow[t]{2}{*}{78} & 47.42 & - & $0.32 \pm 0.01$ & 2243 & 2246 & 9-hexyl-Heptadecane & KI and MS \\
\hline & Total & 98.55 & 99.64 & & & & \\
\hline
\end{tabular}

${ }^{\mathrm{a}}$ Rt: retention time; ${ }^{\mathrm{b}}$ values are mean $(n=2) \pm \mathrm{SD}$ of Saudi ecospecies; ${ }^{\mathrm{c}}$ Egyptian ecospecies; ${ }^{\mathrm{d}}$ literature Kovats retention index; e experimental Kovats retention index; MS: mass spectral data of compounds; KI: Kovats indices with those of Wiley Spectral Library collection and National 104 Institute of Standards and Technology (NIST) Library database.

The analysis of the data revealed that the EOs of the two plant samples were very rich with terpenoids, with respective concentrations of $95.78 \%$ and $66.17 \%$ in addition to carotenoids ( $2.77 \%$ and $20.15 \%$, respectively). The variations in the quantitative and qualitative analysis of EOs of the two plant samples were attributed directly to the environmental and climate variations between the Saudi and Egyptian environments [28,29].

More in-depth data indicated that the EO of the Saudi P. undulata contained mainly terpenoids, including almost equal concentrations of mono $(46.27 \%)$ and sesquiterpenes $(49.51 \%)$ with traces of carotenoids and a complete absence of diterpenoids and hydrocarbons. In comparison, the chemical characterization of the EO of the Egyptian plant showed that terpenoids were the major compounds, including minor elements of monoterpenes $(6.40 \%)$ and abundance of sesquiterpenes $(59.77 \%)$, as well as a high concentration of carotenoids. Similarly, the EO of the Egyptian plant was characterized by the complete absence of diterpenes and the presence of a remarkable concentration of hydrocarbons. The sesquiterpenes were found as major constituents of the EOs of both ecospecies (Saudi and Egyptian); this result was different than those reported for Yemeni leaves $(2.1 \%)$ [13], Iranian aerial parts $(0.5 \%)$ [15], and Egyptian aerial parts $(0.6 \%)$ [20] of P. undulata. The sesquiterpenes in the EOs of Saudi and Egyptian ecospecies were categorized as sesquiterpene hydrocarbons (9.17\% and $4.74 \%)$, and oxygenated sesquiterpenes $(40.34 \%$ and $55.03 \%)$. Isoshyobunone (7.67\%), 6-epi-Shyobunol (6.51\%), spathulenol $(3.43 \%)$, and trans-nerolidol $(3.33 \%)$ represented the main oxygenated sesquiterpene of EO of the Saudi plant. In comparison, spathulenol (30.86\%), $\alpha$-bisabolol (6.34\%), 4,4-dimethyltetracyclo[6.3.2.0(2,5).0(1,8)]tridecan-9-ol $(4.68 \%)$, and $\tau$-cadinol $(3.65 \%)$ were found to be the abundant oxygenated sesquiterpenes of EO of Egyptian ecospecies. Most of the studied ecospecies of $P$. undulata have been described as non-rich of sesquiterpene $[13,15,20]$. However, EOs of other Pulicaria species such as P. somalensis [1], P. dysenterica [30], and $P$. gnaphalodes [31] were reported as rich in sesquiterpene.

Numerous Pulicaria plants were described to have spathulenol as minor and/or major compounds of their EOs such as P. somalensis [1] and P. stephanocarpa [32]. $\alpha$-Bisabolol was detected as the main sesquiterpene in EOs derived from some Pulicaria species such as P. somalensis [1], P. dysenterica [30], and P. gnaphalodes [31]. Moreover, the major sesquiterpene, cadinol, in this study has been described as a major component in EO derived from aerial 
parts of the P. undulata collected from the Algerian Sahara [14], while it was reported as minor or trace element in other ecospecies.

Monoterpenes were reported as the main constituents of several Pulicaria ecospecies [13,33]. Saudi P. undulata was found to be in harmony with the reported documents where the monoterpenes represented around half of the total oil (46.27\%) including hydrocarbons $(39.46 \%)$ and oxygenated $(6.81 \%)$ forms of monoterpene. However, the monoterpenes were identified as trace elements $(6.40 \%)$ in the EO of Egyptian plants, including traces of non-oxygenated and oxygenated forms, with respective relative concentrations of $3.04 \%$ and $3.36 \%$. In the EO from the Saudi sample, $\beta$-pinene $(21.14 \%), \alpha$-pinene $(5.08 \%)$, and $\alpha$ terpinolene $(3.84 \%)$ were assigned as the main monoterpene hydrocarbons, while myrtenyl acetate $(2.50 \%)$ and terpinen-4-ol $(1.20 \%)$ were characterized as main oxygenated monoterpenes. Only four monoterpenes were identified from overall compounds of EO of Egyptian ecospecies. $\beta$-Pinene $(1.32 \%)$ was assigned as the main monoterpene hydrocarbons, and carvotanacetone $(3.36 \%)$ was the only identified oxygenated one. Carvotanacetone was stated as the main monoterpene of $P$. undulata collected from Yemen [13] and from the Egyptian Western Desert region $[8,20]$. The present data revealed that the variations in the components in EO of Egyptian and Saudi samples might be attributed to the variations in collection areas, in addition to the environmental conditions such as soil, climate, as well as their genetic pool [23]. The abundance of pinene and myrtenyl derivatives, $\alpha$-terpinolene, terpinen-4-ol was in complete harmony with the data reported from the Iranian $P$. undulata $[15,18]$.

Carotenoid-derived compounds were represented as trace constituents in the EO of the Saudi ecospecies, with a concentration of $2.77 \%$, comprising carotenoids $(1.26 \%)$ and apocarotenoid-derived compounds (1.51\%). Hexahydrofarnesyl acetone was found as the main component in all characterized carotenoid-derived compounds. By contrast, carotenoid-derived compounds derived from the Egyptian EO sample were characterized by high concentration $(20.12 \%)$, representing carotenoid-derived compounds $(2.03 \%)$ and apocarotenoid-derived compounds (18.12\%). Additionally, hexahydrofarnesyl acetone represented the predominated compound in all overall carotenoid-derived compounds. Hexahydrofarnesyl acetone is a common apocarotenoid-derived compound in EOs derived from the plant kingdom such as Hildegardia barteri [34], Stachys tmolea [35], and Bassia muricata [36].

The hydrocarbons represented $13.32 \%$ of the total identified oil of the Egyptian plant involved non-oxygenated $(8.98 \%)$ and oxygenated $(4.34 \%)$ forms. $n$-nonadecane $(1.57 \%)$ and $n$-nonacosane $(1.49 \%)$ were identified as the majors of non-oxygenated hydrocarbons, while cis-9-hexadecenoic acid (3.73\%) represented the main oxygenated hydrocarbons. Hydrocarbons were completely absent from the EO of the Saudi plant, and this result was found in agreement with Iranian P. undulata $[15,18]$.

\subsection{Chemometric Analysis of the EOs of Pulicaria Ecospecies}

The application of the EOs profiles of the 2 ecotypes of P. undulata and the other 11 ecotypes were subjected to principal component multivariate data analysis (PCA) and agglomerative hierarchical clustering (AHC). The cluster analysis revealed that the EOs could be categorized into four clusters. Cluster-I consisted of the Iran-Baluchestan ecotype, while the EOs of the presently studied ecospecies (Saudi and Egyptian) were grouped as cluster-II. Further, the Egypt-Elba Mountain-2 and Egypt-Sinai ecospecies showed a close correlation, and therefore, they were grouped as cluster-III. Finally, cluster-IV contained Iranian (Iran-Baluchestan, Iran-Fars, and Iran-Hormozgan samples), Algerian, Sudanian, Yemeni, Egyptian (Elba Mountain-2, and Sadat) ecospecies (Figure 2a). 
a)
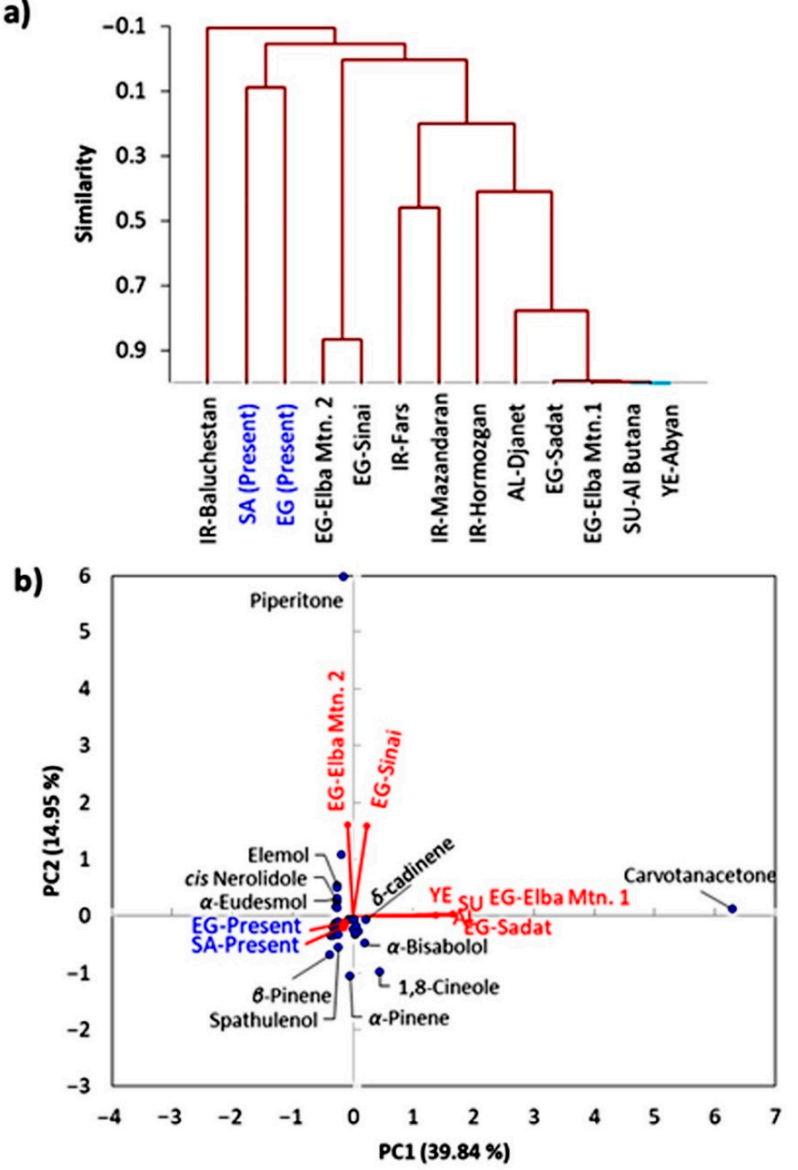

Figure 2. Chemometric analysis of the essential oil of different Pulicaria undulata ecospecies: (a) agglomerative hierarchical clustering (AHC) and (b) principal components analysis (PCA). SA: Suadi, EG: Egyptian, IR: Iranian, AL: Algerian, SU: Sudanian, and YE: Yemeni. The blue color represents the present samples.

The PCA score plot showed the distant separation of Egypt-Elba Mountain-2 and Egypt-Sinai ecospecies in the PC2, while Egypt-Elba Mountain-2, Egypt Sadat, Yemeni, Algerian, and Sudanian ecospecies were distantly distributed along the right side of the PC1 (Figure 2b). Conversely, the present samples (Saudi and Egyptian) as well as Iranian and Algerian were clustered together in the center of the PCA and had positive score values. In addition, the examination of the loading plot showed that piperitone was the most correlated/abundant compound in Egypt-Elba Mountain-2 and Egypt-Sinai ecospecies. However, carvotanacetone showed an abundance in Egypt-Elba Mountain-2, Egypt Sadat, Yemeni, Algerian, and Sudanian ecospecies. The detected variation among different ecospecies could be ascribed to the effect of climatic and environmental conditions, as well as the genetic characteristics $[22,25,26,37]$.

\subsection{Phytotoxic Activity of P. undulata EOs}

The EOs of both Saudi and Egyptian ecotypes of P. undulata showed significant phytotoxic activity against seed germination and seedling growth of the noxious weed B. pilosa (Figure 3). At the highest concentration $\left(100 \mu \mathrm{L} \mathrm{L}^{-1}\right)$, EOs of Saudi ecospecies showed inhibition of germination, shoot growth, and root growth of B. pilosa by $66.67 \%$, $74.59 \%$, and $83.47 \%$, respectively, while the Egyptian species showed inhibition values of $86.67 \%, 79.23 \%$, and $94.17 \%$, respectively (Figure 3 ). Based on the $\mathrm{IC}_{50}$, the Saudi ecospecies showed $\mathrm{IC}_{50}$ values of $72.83,72.84$, and $44.55 \mu \mathrm{L} \mathrm{L}^{-1}$ regrading germination, shoot growth, and root growth of B. pilosa, respectively. However, the Egyptian ecospecies showed $\mathrm{IC}_{50}$ values of $42.42,65.71$, and $40.70 \mu \mathrm{L} \mathrm{L}^{-1}$, respectively (Figure 3). 
a)
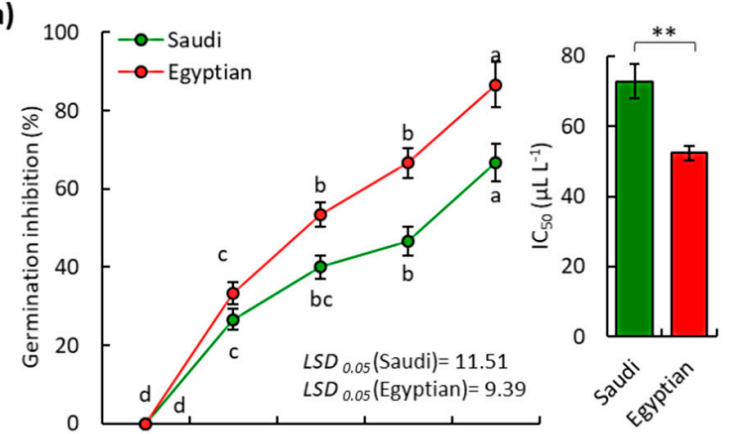

b)
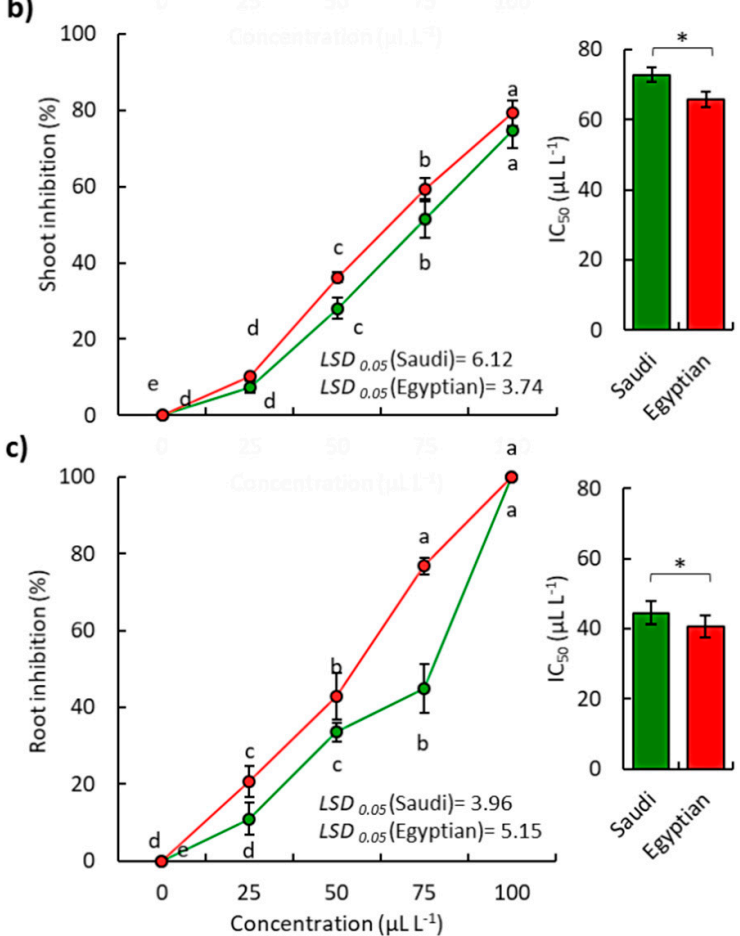

Figure 3. Phytotoxic effect of the EOs extracted from the aerial parts of both Saudi and Egyptian ecotypes of $P$. undulata on the (a) germination of seeds, (b) shoot growth, and (c) root growth of the weed Bidens pilosa. Different letters on each line mean significant differences (one-way randomized blocks ANOVA). Data are mean value $(n=3)$, and the bars represent the standard error. ${ }^{*} p<0.05$, ** $p<0.01$.

It was evident that the Egyptian ecospecies were more effective against $B$. pilosa than Saudi ecospecies, which could be ascribed to the variation in the quality and quantity of the chemical composition of the EO. In this study, the Egyptian ecospecies were richer in oxygenated compounds than the Saudi ones. EOs rich in oxygenated compounds have been reported to possess more activity [38-41]. The phytotoxic activity of the EO from Egyptian ecospecies might be attributed to its major compounds such as spathulenol, hexahydrofarnesyl acetone, $\alpha$-bisabolol, and $\tau$-cadinol. Additionally, the Saudi ecospecies had $\beta$-pinene, isoshyobunone, 6-epi-shyobunol, $\alpha$-pinene, and $\alpha$-terpinolene as major compounds. Moreover, $\tau$-cadinol was identified as a major compound in the EO of Cullen plicata, where it showed strong phytotoxic activity against B. pilosa and Urospermum picroides [38]. Additionally, $\tau$-cadinol was reported in a high concentration of the EO of Rhynchosia minima, which showed significant allelopathic activity against Dactyloctenium aegyptium and Rumex dentatus [42]. However, $\alpha$-bisabolol, as a major compound of the Egyptian ecospecies in the present study, has not been reported to possess phytotoxicity; therefore, further study is recommended for its characterization as an allelochemical compound. 
In the Egyptian ecospecies, the major compound, spathulenol (30.86\%), has also been reported as major compounds of EOs with substantial phytotoxic activity such as Launaea mucronata [26], Xanthium strumarium [37], Eucalyptus camaldulensis [43], Teucrium arduini [44], and Symphyotrichum squamatum [25]. Moreover, hexahydrofarnesyl acetone $(18.12 \%)$, was determined in a high concentration of the EO, which exhibited strong phytotoxicity such as Heliotropium curassavicum [23], Launaea nudicaulis, Launaea mucronata [26], and Bassia muricata [36].

Otherwise, the main compound in the EO of Saudi ecospecies, $\beta$-pinene $(21.14 \%)$, has been reported as the main compound of EOs of various plants that have exhibited phytotoxic activity such as Schinus terebinthifolius [45], Symphyotrichum squamatum [25], Pinus brutia, Pinus pinea [46], Lavandula angustifolia [44], and Heterothalamus psiadioides [47]. The other major compounds of the Saudi ecospecies have also been reported in EOs with significant phytotoxicity $[1,46,48]$. Additionally, the present data showed that the roots were more sensitive to the EO than shoots since roots were directly exposed to the EO. Moreover, root cells have more permeability than the cells of the shoot [22,38].

Results also indicated that the EOs of Saudi and Egyptian ecospecies showed more inhibitory activity against the weed D. aegyptium than B. pilosa (Figure 4).

a)
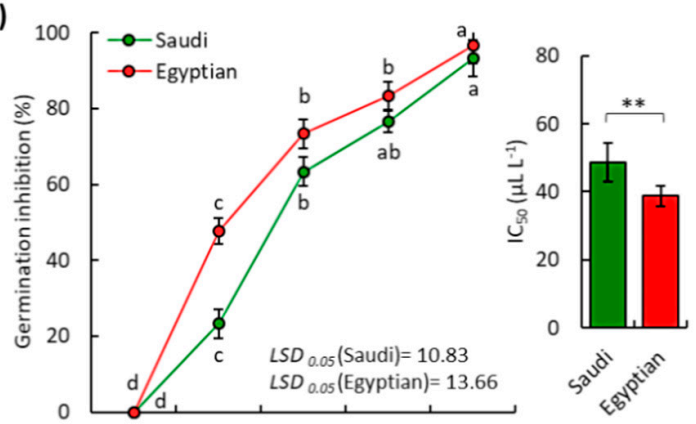

b)
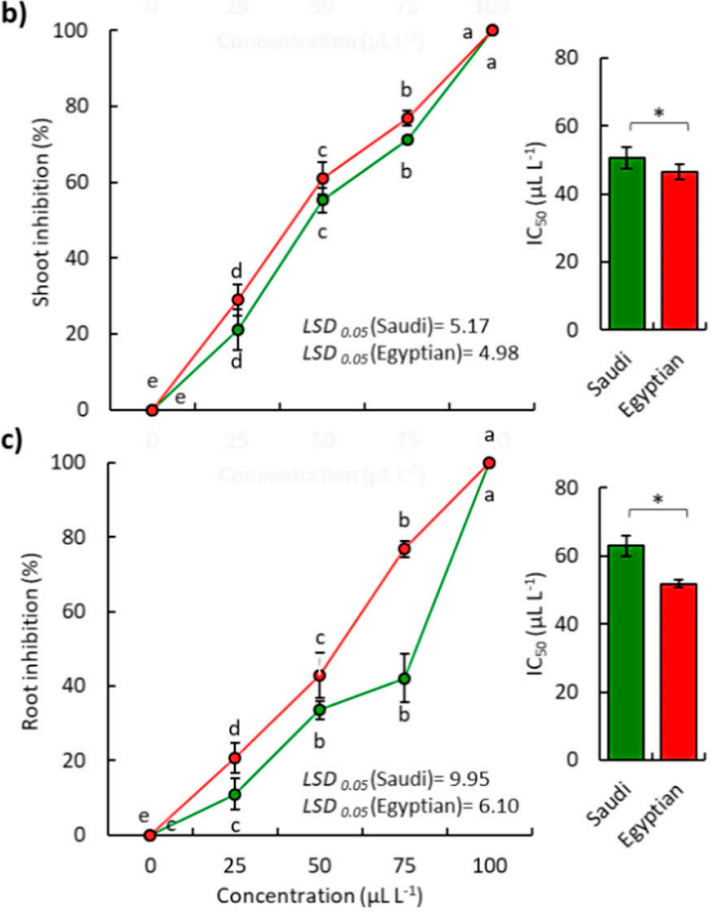

Figure 4. Phytotoxic effect of the EOs extracted from the aerial parts of both Saudi and Egyptian ecotypes of P. undulata on the (a) germination of seeds, (b) shoot growth, and (c) root growth of the weed Dactyloctenium aegyptium. Different letters on each line mean significant differences (one-way randomized blocks ANOVA). Data are mean value $(n=3)$ and the bars represent the standard error. ${ }^{*} p<0.05,{ }^{* *} p<0.01$. 
At the highest concentration of the Saudi EOs $\left(100 \mu \mathrm{L} \mathrm{L}^{-1}\right)$, the D. aegyptium seedling growth was completely inhibited. However, the germination was reduced by $93.33 \%$, while the Egyptian ecospecies showed $96.67 \%$. Based on the $\mathrm{IC}_{50}$ values, the EO of the Saudi ecospecies showed $\mathrm{IC}_{50}$ values of $48.61,50.49$, and $62.92 \mu \mathrm{L} \mathrm{L}^{-1}$ for germination, shoot growth, and root growth of D. aegyptium, respectively, while the Egyptian ecospecies attained $\mathrm{IC}_{50}$ values of $38.84,46.59$, and $51.87 \mu \mathrm{L} \mathrm{L}^{-1}$, respectively.

\section{Materials and Methods}

\subsection{Plant Samples Collection and Preparation}

The aerial parts of Saudi P. undulata were collected from the Wadi Alsahbaa, Alkharj, Riyadh region $\left(24^{\circ} 16^{\prime} 34.1^{\prime \prime} \mathrm{N} 47^{\circ} 56^{\prime} 11.3^{\prime \prime} \mathrm{E}\right)$, while the Egyptian sample was collected from Wadi Hagoul, the Eastern Desert, Egypt $\left(30^{\circ} 00^{\prime} 38.2^{\prime \prime} \mathrm{N} 32^{\circ} 05^{\prime} 35.5^{\prime \prime}\right.$ E), during spring of 2019. The specimens were authenticated according to Tackholm [49] and Boulos [50]. Voucher specimens were prepared and deposited in the herbarium of the Department of Botany, Faculty of Science, Mansoura University with No. Mans.001162117 and Mans.001162118.

The samples were collected from two populations of $P$. undulata in separate plastic bags and immediately transferred to the lab. The samples were dried in a shaded place at room temperature $\left(25 \pm 3^{\circ} \mathrm{C}\right)$ for 7 days, crushed into powder using a grinder (IKA ${ }^{\circledR}$ MF 10 Basic Microfine Grinder Drive, Breisgau, Germany) at a dimension of $3.0 \mathrm{~mm}$, and packed in paper bags.

\subsection{EOs Extraction, GC-MS Analysis, and Chemical Compounds Identification}

About $150 \mathrm{~g}$ of the prepared samples of $P$. undulata were extracted with hydrodistillation via a Clevenger-type apparatus for $3 \mathrm{~h}$. The oils were collected, water was removed using $0.5 \mathrm{~g}$ of anhydrous sodium sulfate, and stored in glass vials in the fridge $\left(-4{ }^{\circ} \mathrm{C}\right)$ till further analysis [29]. Two samples of the plant were extracted by the same protocol afforded two samples of EOs. The two extracted EOs were analyzed via gas chromatography-mass spectrometry (GC-MS) at the National Research Center, Giza, Egypt, as described in our previously documented work $[25,26,48,51]$. Briefly, the apparatus has TRACE GC Ultra Gas Chromatographs (THERMO Scientific ${ }^{\mathrm{TM}}$ Corporate, Waltham, MA, USA), together with Thermo Scientific ISQ ${ }^{\mathrm{TM}} \mathrm{EC}$ single quadrupole mass spectrometer. The GC-MS system is equipped with a TR-5 MS column $(0.25 \mu \mathrm{m}$ film thickness, $30 \mathrm{~m} \times 0.32 \mathrm{~mm}$ internal diameter). Helium was used as a carrier gas at a flow rate of $1.0 \mathrm{~mL} \mathrm{~min}^{-1}$, with a divided ratio of $1: 10$. The temperature program was $60^{\circ} \mathrm{C}$ for $1 \mathrm{~min}$, rising by $4.0^{\circ} \mathrm{C} \mathrm{min}-1$ to $240^{\circ} \mathrm{C}$, and held for $1 \mathrm{~min}$. An aliquot of $1 \mu \mathrm{L}$ of the EO sample in hexane was injected at a ratio of 1:10 $(v / v)$, and the detector and injector were adjusted at $210{ }^{\circ} \mathrm{C}$. Mass spectra were recorded by electron ionization (EI) at $70 \mathrm{eV}$, using a spectral range of $m / z 40-450$. The chemical compounds identification was accomplished by Automated Mass spectral Deconvolution and Identification (AMDIS) software, as well as Wiley Spectral Library collection, NIST Library database (Gaithersburg, MD, USA; Wiley, Hoboken, NJ, USA), which were used for retention indices relative to n-alkanes $\left(\mathrm{C}_{8}-\mathrm{C}_{22}\right)$, or appraisal of the mass spectrum with authentic standards.

\subsection{Phytotoxic Activity Estimation of the EOs}

The extracted EOs were tested for their phytotoxicity against two noxious weeds Dactyloctenium aegyptium and Bidens pilosa. The seeds of D. aegyptium were collected from cultivated fields near the Mediterranean coast, at Gamasa City, northern Egypt $\left(31^{\circ} 27^{\prime} 03.9^{\prime \prime} \mathrm{N} 31^{\circ} 27^{\prime} 44.8^{\prime \prime} \mathrm{E}\right)$, while the seeds of B. pilosa were collected from a garden in Mansoura University campus, Mansoura, Egypt ( $\left.31^{\circ} 02^{\prime} 40.2^{\prime \prime} \mathrm{N} 31^{\circ} 21^{\prime} 18.4^{\prime \prime} \mathrm{E}\right)$. The homogenous and ripe seeds were selected, sterilized with $0.3 \%$ sodium hypochlorite, rinsed with distilled and sterilized water, dried, and stored in sterilized vials.

The phytotoxicity experiments were conducted in vitro following the methodology described by Abd El-Gawad et al. [38]. In brief, 20 seeds of the weed were transferred to a 
Petri plate lined with Whatman No. 1 filter paper wetted with $4 \mathrm{~mL}$ of each concentration of the EOs $\left(25,50,75\right.$, and $\left.100 \mu \mathrm{L} \mathrm{L}^{-1}\right)$. Different concentrations of the EOs were prepared using 1\% Tween ${ }^{\circledR} 80$ (Sigma-Aldrich, Darmstadt, Germany) as an emulsifier. The plates were sealed with Parafilm ${ }^{\circledR}$ tape and incubated in a growth chamber adjusted with a temperature of $25^{\circ} \mathrm{C}$ and light/dark cycle of $12 / 12 \mathrm{~h}$. Besides, Tween ${ }^{\circledR} 80$ was used as a control treatment. After seven days of incubation, the germinated seeds were counted and the length of shoots and roots of the seedlings were measured. The inhibition of germination and seedling growth were calculated based on the following equation:

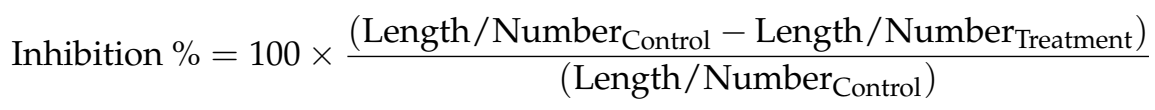

The $\mathrm{IC}_{50}$ (the concentration of the $\mathrm{EO}$ required to reduce the germination or growth by $50 \%$ ) was calculated using MS-Excel.

\subsection{Data Analysis}

The experiment of phytotoxicity was repeated three times with three replications. The data of the inhibition were subjected to one-way ANOVA, followed by Duncan's test using CoStat program (version 6.311, CoHort Software, Monterey, CA, USA), while the $\mathrm{IC}_{50}$ values were subjected to a two-tailed $t$-test using MS-EXCEL. To make a holistic categorization of the EOs of the two studied ecospecies (Saudi and Egyptian) and other reported ecospecies (Algerian, Egyptian, Iranian, Sudanian, and Yemeni), we constructed a data matrix of the 30 major chemical compounds, with concentration $>3 \%$, from 11 ecospecies. The matrix was subjected to Principal component multivariate data analysis (PCA) and agglomerative hierarchical clustering (AHC) using the XLSTAT Statistical Software package (version 2018, Addinsoft Inc., New York, NY, USA).

\section{Conclusions}

The EO composition of the Saudi and Egyptian ecospecies of P. undulata showed substantial variation in both quantity and quality. The Saudi ecospecies had 61 compounds, with $\beta$-pinene, isoshyobunone, 6-epi-shyobunol, $\alpha$-pinene, and $\alpha$-terpinolene as major compounds, while the EO of the Egyptian ecospecies attained a lower number (34 compounds), with spathulenol, hexahydrofarnesyl acetone, $\alpha$-bisabolol, and $\tau$-cadinol as main compounds. This variation could be attributed to the difference in the environmental and climatic conditions. The EO of the Egyptian ecospecies showed more phytotoxic activity against $D$. aegyptium than $B$. pilosa, as well as more phytotoxic, compared with the Saudi ecospecies. This variation might be ascribed to the difference in their major constituents. Therefore, further study is recommended for the characterization of authentic materials of these compounds as allelochemicals against various weeds, either singular or in combination.

Author Contributions: Conceptualization, A.M.A.-E., A.M.A., Y.A.E.-A. and A.I.E.; formal analysis, A.M.A.-E., Y.A.E.-A., A.E.-N.G.E.G., D.H.A.-D. and A.I.E.; investigation, A.M.A.-E., S.L.A.-R., A.M.A., A.E.-N.G.E.G., G.B., Y.A.E.-A. and A.I.E.; writing—original draft preparation, A.M.A.-E., Y.A.E.-A., and A.I.E.; writing-review and editing, A.M.A.-E., S.L.A.-R., A.M.A., Y.A.E.-A., A.E.-N.G.E.G., E.O., D.H.A.-D., G.B., H.S.K. and A.I.E. All authors have read and agreed to the published version of the manuscript.

Funding: This study was funded by the Researchers Supporting Project, Number (RSP-2021/403), King Saud University, Riyadh, Saudi Arabia.

Institutional Review Board Statement: Not applicable.

Informed Consent Statement: Not applicable.

Data Availability Statement: Not applicable. 
Acknowledgments: The authors extend their appreciation to the Researchers Supporting Project, Number (RSP-2021/403), King Saud University, Riyadh, Saudi Arabia.

Conflicts of Interest: The authors declare no conflict of interest.

Sample Availability: Samples of the compounds are not available from the authors.

\section{References}

1. Assaeed, A.; Elshamy, A.; El Gendy, A.E.-N.; Dar, B.; Al-Rowaily, S.; Abd-ElGawad, A. Sesquiterpenes-rich essential oil from above ground parts of Pulicaria somalensis exhibited antioxidant activity and allelopathic effect on weeds. Agronomy 2020, 10, 399. [CrossRef]

2. Al-Maqtari, Q.A.; Mahdi, A.A.; Al-Ansi, W.; Mohammed, J.K.; Wei, M.; Yao, W. Evaluation of bioactive compounds and antibacterial activity of Pulicaria jaubertii extract obtained by supercritical and conventional methods. J. Food Meas. Charact. 2020, 15, 449-456. [CrossRef]

3. Elshamy, A.I.; Mohamed, T.A.; Marzouk, M.M.; Hussien, T.A.; Umeyama, A.; Hegazy, M.E.F.; Efferth, T. Phytochemical constituents and chemosystematic significance of Pulicaria jaubertii E. Gamal-Eldin (Asteraceae). Phytochem. Lett. 2018, 24, 105-109. [CrossRef]

4. Hegazy, M.-E.F.; Matsuda, H.; Nakamura, S.; Yabe, M.; Matsumoto, T.; Yoshikawa, M. Sesquiterpenes from an Egyptian herbal medicine, Pulicaria undulate, with inhibitory effects on nitric oxide production in RAW264. 7 macrophage cells. Chem. Pharm. Bull. 2012, 60, 363-370. [CrossRef]

5. Hammiche, V.; Maiza, K. Traditional medicine in Central Sahara: Pharmacopoeia of Tassili N'ajjer. J. Ethnopharmacol. 2006, 105, 358-367. [CrossRef]

6. Mohammed, A.B.; Yagi, S.; Tzanova, T.; Schohn, H.; Abdelgadir, H.; Stefanucci, A.; Mollica, A.; Mahomoodally, M.F.; Adlan, T.A.; Zengin, G. Chemical profile, antiproliferative, antioxidant and enzyme inhibition activities of Ocimum basilicum L. and Pulicaria undulata (L.) CA Mey. grown in Sudan. S. Afr. J. Botany 2020, 132, 403-409. [CrossRef]

7. Hussein, S.R.; Marzouk, M.M.; Soltan, M.M.; Ahmed, E.K.; Said, M.M.; Hamed, A.R. Phenolic constituents of Pulicaria undulata (L.) CA Mey. sub sp. undulata (Asteraceae): Antioxidant protective effects and chemosystematic significances. J. Food Drug Anal. 2017, 25, 333-339. [CrossRef] [PubMed]

8. Mustafa, A.M.; Eldahmy, S.I.; Caprioli, G.; Bramucci, M.; Quassinti, L.; Lupidi, G.; Beghelli, D.; Vittori, S.; Maggi, F. Chemical composition and biological activities of the essential oil from Pulicaria undulata (L.) CA Mey. Growing wild in Egypt. Nat. Prod. Res. 2020, 34, 2358-2362. [CrossRef]

9. Issa, M.Y.; Ezzat, M.I.; Sayed, R.H.; Elbaz, E.M.; Omar, F.A.; Mohsen, E. Neuroprotective effects of Pulicaria undulata essential oil in rotenone model of parkinson's disease in rats: Insights into its anti-inflammatory and anti-oxidant effects. S. Afr. J. Bot. 2020, 132, 289-298. [CrossRef]

10. Fahmi, A.A.; Abdur-Rahman, M.; Naser, A.F.A.; Hamed, M.A.; Abd-Alla, H.I.; Shalaby, N.M.; Nasr, M.I. Chemical composition and protective role of Pulicaria undulata (L.) CA Mey. subsp. undulata against gastric ulcer induced by ethanol in rats. Heliyon 2019, 5, e01359.

11. Abdallah, H.M.; Mohamed, G.A.; Ibrahim, S.R.M.; Asfour, H.Z.; Khayat, M.T. Undulaterpene A: A new triterpene fatty acid ester from Pulicaria undulata. Pharmacogn. Mag. 2019, 15, 671-674. [CrossRef]

12. Rasool, N.; Rashid, M.A.; Khan, S.S.; Ali, Z.; Zubair, M.; Ahmad, V.U.; Khan, S.N.; Choudhary, M.I.; Tareen, R.B. Novel $\alpha$-glucosidase activator from Pulicaria undulata. Nat. Prod. Commun. 2013, 8, 757-759. [CrossRef]

13. Ali, N.A.A.; Sharopov, F.S.; Alhaj, M.; Hill, G.M.; Porzel, A.; Arnold, N.; Setzer, W.N.; Schmidt, J.; Wessjohann, L. Chemical composition and biological activity of essential oil from Pulicaria undulata from Yemen. Nat. Prod. Commun. 2012, 7, 257-260. [CrossRef] [PubMed]

14. Boumaraf, M.; Mekkiou, R.; Benyahia, S.; Chalchat, J.-C.; Chalard, P.; Benayache, F.; Benayache, S. Essential oil composition of Pulicaria undulata (L.) DC.(Asteraceae) growing in Algeria. Int. J. Pharmacogn. Phytochem. Res. 2016, 8, 746-749.

15. Ravandeh, M.; Valizadeh, J.; Noroozifar, M.; Khorasani-Motlagh, M. Screening of chemical composition of essential oil, mineral elements and antioxidant activity in Pulicaria undulata (L.) CA Mey from Iran. J. Med. Plants Res. 2011, 5, $2035-2040$.

16. Ahmed, S.; Ibrahim, M. Chemical investigation and antimicrobial activity of Francoeuria crispa (Forssk) Grown Wild in Egypt. J. Mater. Environ. Sci. 2017, 9, 1-6. [CrossRef]

17. EL-Kamali, H.H.; Yousif, M.O.; Ahmed, O.I.; Sabir, S.S. Phytochemical analysis of the essential oil from aerial parts of Pulicaria undulata (L.) Kostel from Sudan. Ethnobot. Leafl. 2009, 2009, 467-471.

18. Nematollahi, F.; Rustaiyan, A.; Larijani, K.; Nadimi, M.; Masoudi, S. Essential oil composition of Artemisia biennisz Willd. and Pulicaria undulata (L.) CA Mey., two compositae herbs growing wild in Iran. J. Essent. Oil Res. 2006, 18, 339-341. [CrossRef]

19. Javadinamin, A.; Asgarpanah, J. Essential oil composition of Francoeuria undulata (L.) Lack. growing wild in Iran. J. Essent. Oil Bear. Plants 2014, 17, 875-879. [CrossRef]

20. Dekinash, M.F.; Abou-Hashem, M.M.; Beltagy, A.M.; El-Fiky, F.K. GC/MS profiling, in-vitro cytotoxic and antioxidant potential of the essential oil of Pulicaria crispa (Forssk) growing in Egypt. Int. J. Pharmacogn. Chin. Med. 2019, 3, 000175.

21. Hassan, E.M.; El Gendy, A.E.-N.G.; Abd-ElGawad, A.M.; Elshamy, A.I.; Farag, M.A.; Alamery, S.F.; Omer, E.A. Comparative chemical profiles of the essential oils from different varieties of Psidium guajava L. Molecules 2021, 26, 119. [CrossRef] [PubMed] 
22. Abd-ElGawad, A.M.; El-Amier, Y.A.; Assaeed, A.M.; Al-Rowaily, S.L. Interspecific variations in the habitats of Reichardia tingitana (L.) Roth leading to changes in its bioactive constituents and allelopathic activity. Saudi J. Biol. Sci. 2020, 27, 489-499. [CrossRef]

23. Abd-ElGawad, A.M.; Elshamy, A.I.; Al-Rowaily, S.L.; El-Amier, Y.A. Habitat affects the chemical profile, allelopathy, and antioxidant properties of essential oils and phenolic enriched extracts of the invasive plant Heliotropium curassavicum. Plants 2019, 8, 482. [CrossRef] [PubMed]

24. Seidi Damyeh, M.; Niakousari, M. Ohmic hydrodistillation, an accelerated energy-saver green process in the extraction of Pulicaria undulata essential oil. Ind. Crop. Prod. 2017, 98, 100-107. [CrossRef]

25. Abd-ElGawad, A.M.; Elshamy, A.; El-Amier, Y.A.; El Gendy, A.; Al-Barati, S.; Dar, B.; Al-Rowaily, S.; Assaeed, A. Chemical composition variations, allelopathic, and antioxidant activities of Symphyotrichum squamatum (Spreng.) Nesom essential oils growing in heterogeneous habitats. Arab. J. Chem. 2020, 13, 237-4245. [CrossRef]

26. Elshamy, A.I.; Abd-ElGawad, A.M.; El-Amier, Y.A.; El Gendy, A.E.N.G.; Al-Rowaily, S.L. Interspecific variation, antioxidant and allelopathic activity of the essential oil from three Launaea species growing naturally in heterogeneous habitats in Egypt. Flavour Fragr. J. 2019, 34, 316-328. [CrossRef]

27. Fayed, E.M.; Abd-EIGawad, A.M.; Elshamy, A.I.; El-Halawany, E.S.F.; EI-Amier, Y.A. Essential oil of Deverra tortuosa aerial parts: Detailed chemical profile, allelopathic, antimicrobial, and antioxidant activities. Chem. Biodivers. 2021, 18, e2000914. [CrossRef] [PubMed]

28. Abd-ElGawad, A.M.; El Gendy, A.E.-N.G.; Assaeed, A.M.; Al-Rowaily, S.L.; Alharthi, A.S.; Mohamed, T.A.; Nassar, M.I.; Dewir, Y.H.; Elshamy, A.I. Phytotoxic effects of plant essential oils: A systematic review and structure-activity relationship based on chemometric analyses. Plants 2021, 10, 36. [CrossRef]

29. Al-Rowaily, S.L.; Abd-ElGawad, A.M.; Assaeed, A.M.; Elgamal, A.M.; Gendy, A.E.-N.G.E.; Mohamed, T.A.; Dar, B.A.; Mohamed, T.K.; Elshamy, A.I. Essential oil of Calotropis procera: Comparative chemical profiles, antimicrobial activity, and allelopathic potential on weeds. Molecules 2020, 25, 5203. [CrossRef]

30. Mumivand, H.; Rustaii, A.-R.; Jahanbin, K.; Dastan, D. Essential oil composition of Pulicaria dysenterica (L.) Bernh from Iran. J. Essent. Oil Bear. Plants 2010, 13, 717-720. [CrossRef]

31. Bashi, D.S.; Ghani, A.; Asili, J. Essential oil composition of Pulicaria gnaphalodes (Vent.) Boiss. growing in Iran. J. Essent. Oil Bear. Plants 2013, 16, 252-256. [CrossRef]

32. Ali, N.A.A.; Crouch, R.A.; Al-Fatimi, M.A.; Arnold, N.; Teichert, A.; Setzer, W.N.; Wessjohann, L. Chemical composition, antimicrobial, antiradical and anticholinesterase activity of the essential oil of Pulicaria stephanocarpa from Soqotra. Nat. Prod. Commun. 2012, 7, 113-116. [CrossRef]

33. Fawzy, G.A.; Al Ati, H.Y.; El Gamal, A.A. Chemical composition and biological evaluation of essential oils of Pulicaria jaubertii. Pharmacogn. Mag. 2013, 9, 28-33. [CrossRef] [PubMed]

34. Balogun, O.S.; Ajayi, O.S.; Adeleke, A.J. Hexahydrofarnesyl acetone-rich extractives from Hildegardia barteri. J. Herbs Spices Med. Plants 2017, 23, 393-400. [CrossRef]

35. Demiray, H.; Tabanca, N.; Estep, A.S.; Becnel, J.J.; Demirci, B. Chemical composition of the essential oil and n-hexane extract of Stachys tmolea subsp. tmolea Boiss., an endemic species of Turkey, and their mosquitocidal activity against dengue vector Aesdes aegypti. Saudi Pharm. J. 2019, 27, 877-881. [PubMed]

36. Abd-ElGawad, A.; El Gendy, A.E.-N.; El-Amier, Y.; Gaara, A.; Omer, E.; Al-Rowaily, S.; Assaeed, A.; Al-Rashed, S.; Elshamy, A. Essential oil of Bassia muricata: Chemical characterization, antioxidant activity, and allelopathic effect on the weed Chenopodium murale. Saudi J. Biol. Sci. 2020, 27, 1900-1906. [CrossRef] [PubMed]

37. Abd El-Gawad, A.M.; Elshamy, A.I.; El Gendy, A.E.-N.; Gaara, A.; Assaeed, A.M. Volatiles profiling, allelopathic activity, and antioxidant potentiality of Xanthium strumarium leaves essential oil from Egypt: Evidence from chemometrics analysis. Molecules 2019, 24, 584. [CrossRef]

38. Abd El-Gawad, A.; El Gendy, A.; Elshamy, A.; Omer, E. Chemical composition of the essential oil of Trianthema portulacastrum L. Aerial parts and potential antimicrobial and phytotoxic activities of its extract. J. Essent. Oil Bear. Plants 2016, 19, 1684-1692. [CrossRef]

39. Elshamy, A.I.; Ammar, N.M.; Hassan, H.A.; Al-Rowaily, S.L.; Ragab, T.I.; El Gendy, A.E.-N.G.; Abd-ElGawad, A.M. Essential oil and its nanoemulsion of Araucaria heterophylla resin: Chemical characterization, anti-inflammatory, and antipyretic activities. Ind. Crop. Prod. 2020, 148, 112272. [CrossRef]

40. Elshamy, A.I.; Abd-ElGawad, A.M.; El Gendy, A.E.N.G.; Assaeed, A.M. Chemical characterization of Euphorbia heterophylla L. essential oils and their antioxidant activity and allelopathic potential on Cenchrus echinatus L. Chem. Biodivers. 2019, 16, e1900051. [CrossRef]

41. Abd El-Gawad, A.M.; El-Amier, Y.A.; Bonanomi, G. Essential oil composition, antioxidant and allelopathic activities of Cleome droserifolia (Forssk.) Delile. Chem. Biodivers. 2018, 15, e1800392. [CrossRef] [PubMed]

42. Abd El-Gawad, A.M.; El-Amier, Y.A.; Bonanomi, G. Allelopathic activity and chemical composition of Rhynchosia minima (L.) DC. essential oil from Egypt. Chem. Biodivers. 2018, 15, e1700438. [CrossRef]

43. Verdeguer, M.; Blázquez, M.A.; Boira, H. Phytotoxic effects of Lantana camara, Eucalyptus camaldulensis and Eriocephalus africanus essential oils in weeds of Mediterranean summer crops. Biochem. Syst. Ecol. 2009, 37, 362-369. [CrossRef]

44. De Almeida, L.F.R.; Frei, F.; Mancini, E.; De Martino, L.; De Feo, V. Phytotoxic activities of Mediterranean essential oils. Molecules 2010, 15, 4309-4323. [CrossRef] 
45. Pinheiro, P.F.; Costa, A.V.; Tomaz, M.A.; Rodrigues, W.N.; Fialho Silva, W.P.; Moreira Valente, V.M. Characterization of the essential oil of mastic tree from different biomes and its phytotoxic potential on Cobbler's pegs. J. Essent. Oil Bear. Plants 2016, 19, 972-979. [CrossRef]

46. Ulukanli, Z.; Karabörklü, S.; Bozok, F.; Burhan, A.; Erdogan, S.; Cenet, M.; Karaaslan, M.G. Chemical composition, antimicrobial insecticidal, phytotoxic and antioxidant activities of Mediterranean Pinus brutia and Pinus pinea resin essential oils. Chin. J. Nat. Med. 2014, 12, 901-910. [CrossRef]

47. Silva, E.; Overbeck, G.; Soares, G. Phytotoxicity of volatiles from fresh and dry leaves of two Asteraceae shrubs: Evaluation of seasonal effects. S. Afr. J. Botany 2014, 93, 14-18. [CrossRef]

48. Abd-ElGawad, A.M.; Elshamy, A.I.; El-Nasser El Gendy, A.; Al-Rowaily, S.L.; Assaeed, A.M. Preponderance of oxygenated sesquiterpenes and diterpenes in the volatile oil constituents of Lactuca serriola L. revealed antioxidant and allelopathic activity. Chem. Biodivers. 2019, 16, e1900278. [CrossRef]

49. Tackholm, V. Students' Flora of Egypt, 2nd ed.; Cairo University Press: Cairo, Egypt, 1974.

50. Boulos, L. Flora of Egypt; Al Hadara Publishing: Cairo, Egypt, 2002; Volume 3.

51. Saleh, I.; Abd-ElGawad, A.; El Gendy, A.E.-N.; Abd El Aty, A.; Mohamed, T.; Kassem, H.; Aldosri, F.; Elshamy, A.; Hegazy, M.-E.F Phytotoxic and antimicrobial activities of Teucrium polium and Thymus decussatus essential oils extracted using hydrodistillation and microwave-assisted techniques. Plants 2020, 9, 716. [CrossRef] [PubMed] 